\title{
Comparison of the Antibacterial Effects on Subgingival Microflora of Two Different Resorbable Base Materials Containing Doxycycline
}

\author{
İ. Levent Taner ${ }^{1}$, Gönen Özcan ${ }^{1}$, Tanver Doğanay², Metin İscanolu², Berin Taplamacioğlu ${ }^{1}$, \\ S. Elif Gültekin ${ }^{1}$ and Köksal Baloş ${ }^{1}$
}

(Received 12 January and accepted 1 June 1994)

Key words: hydroxypropylmethylcellulose, methylcellulose membranes, doxycycline, subgingival microflora, local antibacterial therapy

\begin{abstract}
A study was conducted to evaluate the effects of local drug delivery on subgingival plaque flora using hydroxypropylmethylcellulose (HPMC) and methylcellulose (MC) base material containing $40 \%$ doxycycline (DOXY). Eleven patients who had at least four pockets exceeding $5 \mathrm{~mm}$ in depth associated with a single rooted tooth were selected from volunteers after an initial examination. Two of the pockets were chosen at random for insertion of the HPMC and MC strips twice a week for $6 \mathrm{w}$. One pocket received no treatment, and the other was debrided and root-planed only. Baseline and follow-up measurements at $0,1,3,6$, and $10 \mathrm{w}$ included probing depth, gingival shrinkage, bleeding on probing and crevicular fluid flow. Subgingival bacterial samples were also taken for dark-field microscopy. In vitro drug release from the HPMC strips was greater than that from MC. Significant improvements in many clinical parameters occurred in the pockets treated with HPMC or MC strips, or mechanical debridement. There was a marked decrease in the relative proportions of motile organisms during and after treatment.
\end{abstract}

\section{Introduction}

Recent etiological studies have defined the relationship between specific plaque microorganisms and periodontal disease progression in longitudinal trials ${ }^{[1-6]}$. It has been shown to be virtually impossible to remove subgingival plaque by routine brushing if the plaque extends more than $2.5 \mathrm{~mm}$ apical to the gingival $\operatorname{margin}^{[7]}$. It has also been reported that conventional subgingival instrumentation leaves significant numbers of pathogenic bacteria in periodontal pockets ${ }^{[8,9]}$. Therefore the use of antibacterial agents as an adjunct in the treatment of periodontal disease has received considerable attention during the past decade $^{[10-13]}$.

Controlled delivery systems designed to be placed into the periodontal pocket can create a longer duration of effective drug concentration at lower dosage ${ }^{[14]}$. Different materials such as acrylic resin strips ${ }^{[15]}$, monolithic fibers ${ }^{[16]}$ and hollow fiber devices ${ }^{[17]}$ have been used for sustained release of antimicrobial agents. Immobilized membranes having excellent properties have also been investigated as a carrier for various pharmacologically active substances ${ }^{[18,19]}$.

In a recent study, a resorbable base material was used to deliver antimicrobial drugs into periodontal pockets, and marked changes in microbial composition were found in pockets treated with either tetracycline or chlorhexidine ${ }^{[20]}$.

The tetracyclines have often been selected because of their broad spectrum and other biological effects $^{[21,22]}$. Semisynthetic doxycycline(DOXY) has proved to be more active than the older tetracyclines ${ }^{[23]}$.

The purpose of the present study was to compare the use of two different resorbable membranes containing DOXY for the treatment of periodontal pockets and to contrast their use with the conventional mechanical technique during a $10 \mathrm{w}$ period.

1 Department of Periodontology, Gazi University School of Dentistry

2 Department of Technology, Gazi University Faculty of Pharmacology

To Whom all correspondence should be addressed:Dr.Gönen Özucan,Department of Pharmacology,G.U.Dental Faculty,8.Cad.,Emek 06510 Ankara,TURKEY 


\section{Materials and Methods}

Informad consent was obtained from all patients participating in the study. Patients with no systemic diseases were selected from among those diagnosed from clinical and radiographic examinations as suffering from chronic periodontitis with the presence of several pockets $\geqq 5 \mathrm{~mm}$ in depth that bled after gentle probing. The patients had not received dental treatment or medication for three months. Eleven subjects ( 8 males and 3 females; mean age $44 \mathrm{yr}$; age range 37 to $45 \mathrm{yr}$ ) presenting with at least 4 periodontal pockets participated.The patients were allocated randomly into four groups as follows:

1) Hydroxypropylmethylcellulose(HPMC)-DOXY strip, 2) Methylcellulose(MC)-DOXY strip, 3) Root planing, 4) Control. Following removal of supragingival calculus professionally, the patients continued their individual routine oral hygiene methods.

One or two resorbable strips were placed at each site and left at the level of the free gingival margin twice a week for $6 \mathrm{w}$. The following parameters were determined at the site of film insertion: gingival crevicular fluid measurements ${ }^{[24]}$, subgingival plaque sampling for dark-field microscopy ${ }^{[25]}$, probing depth, gingival shrinkage, and sulcus bleeding index ${ }^{[26]}$.

\section{Preparation of Drug-containing Membranes}

Drug-containing membranes were prepared as follows: $1.5 \mathrm{~g}$ of HPMC or $1.5 \mathrm{~g}$ of MC powder was dissolved in $38.5 \mathrm{ml}$ of distilled water at $70^{\circ} \mathrm{C}$. The solutions were then cooled to $25^{\circ} \mathrm{C}$. and at this temperature $1 \mathrm{~g}$ of DOXY was added to give a final drug concentration of approximately $40 \%$. The solutions were poured into plates and kept at $30^{\circ} \mathrm{C}$. under reduced pressure for 5 days in order to obtain sheets $0.14 \mathrm{~mm}$ thick.

A model system was also prepared to measure the in vitro release of DOXY from both membranes. In this system the concentration of drug released into the water was determined by measurement of absorbance at $360 \mathrm{~nm}$ in a spectrophotometer at $4,8,12,24,48,72$ and $96 \mathrm{~h}$.

Statistical analysis of the results to determine overall differences between groups, time and membranes were carried out using one-way analysis of variance (ANOVA). In addition, serial changes within each group were assessed by paired $t$ test.

\section{Results}

Cumulative percentage release of DOXY from HPMC and MC membranes in the in vitro model is shown in Fig. 1. The maximum percentage release of DOXY from both HPMC and MC occurred in the first $12 \mathrm{~h}$. However, the release from HPMC membranes seemed to be greater than that from MC membranes.

According to the rate of release diagram in Fig.2, DOXY release, expressed as $\mu \mathrm{g} / \mathrm{h}$, was higher from HPMC membranes than from MC membranes in the first $8 \mathrm{~h}$. After $8 \mathrm{~h}$, the release from MC decreased more rapidly than that from HPMC. At $24 \mathrm{~h}$, the rate of drug release was around $30 \mu \mathrm{g} / \mathrm{h}$ for HPMC and 5 $\mu \mathrm{g} / \mathrm{h}$ for MC. At $72 \mathrm{~h}$, the release from MC was approximately zero, although the release from HPMC was close to $7 \mu \mathrm{g} / \mathrm{h}$.

\section{DOXYCYCLINE}

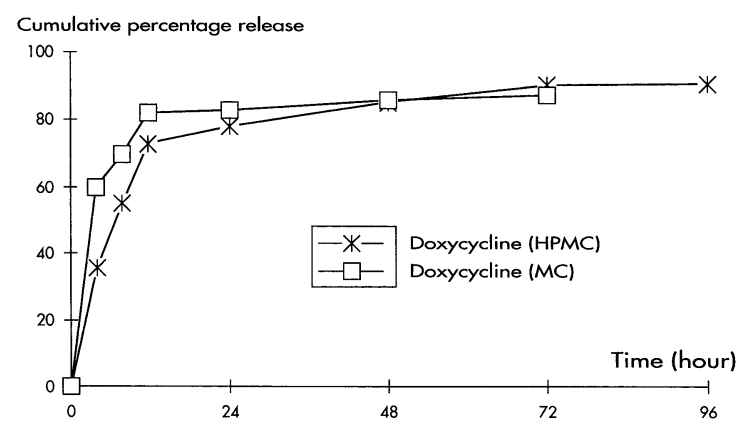

Fig. 1 Cumulative percentage release of DOXY from HPMC and MC membranes 

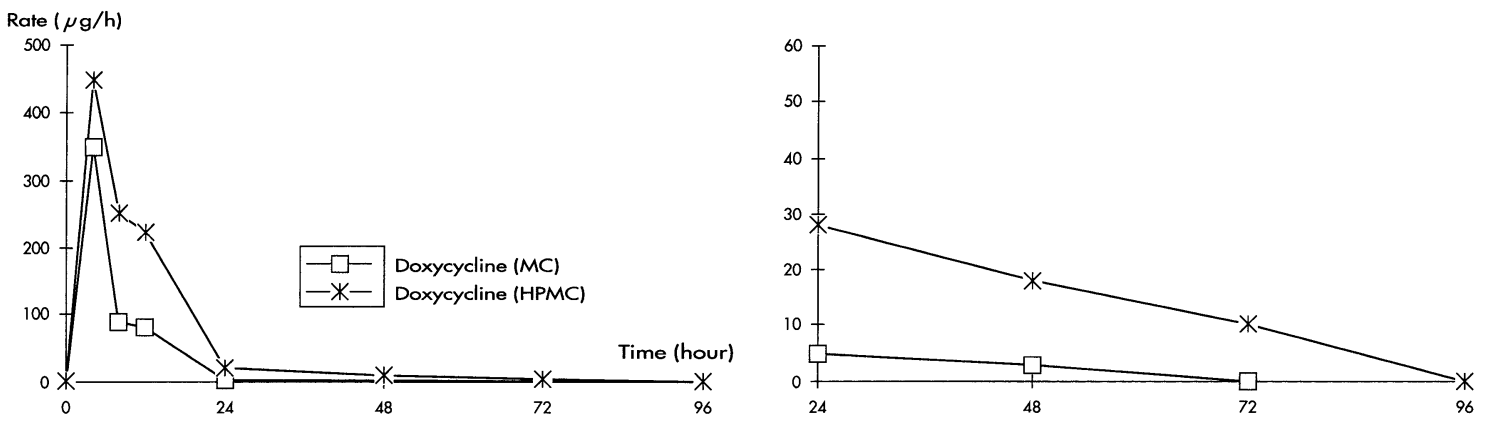

Fig. 2 Rate of release ( $\mu \mathrm{g} / \mathrm{h})$ of DOXY from HPMC and MC membranes

The statistical differences between treatments obtained by analysis of variance are summarized in Table 1. It is apparent that at the baseline there were no significant differences between the treatment groups for any of the measurement parameters. However, after treatment, significant differences were noted between the groups at various visits.

Changes in pocket depth in the different groups are given in Table 2. Intragroup analysis revealed that all treatment groups produced significant and gradually increasing reductions in pocket depths for up to 10 w. The control pockets showed no significant changes. Intergroup comparisons showed that all treatments significantly reduced pocketing in comparison with control pockets $(\mathrm{p}<0.05-<0.001)$.

A summary of the statistical differences between the groups for measurement of gingival shrinkage is given in Table 3. As can be seen, the results of intragroup analysis were similar to those for pocket depth with the exception of the first week. Intergroup analysis also revealed significant improvements in comparison with the control group ( $\mathrm{p}<0.05, \mathrm{p}<0.01$ ).

The results of intragroup analysis for measurement of bleeding score are given in Table 4. Within the control group no significant changes in bleeding occurred. However all the treatment groups showed significant intragroup reductions in bleeding, which were maintained for up to $10 \mathrm{w}$. Reductions in bleeding in the doxycycline groups were more marked than in the root planing group. At one week, the decreased bleeding scores in the treatment groups were not significant.

The results of intragroup analysis for the crevicular fluid measurements are given in Table 5. As shown in the table, crevicular fluid flow changed significantly in the treatment groups whereas no significant changes were detected in the control group. Intergroup analysis, on the other hand, revealed significant differences between the groups at 6 and 10 weeks.

The means and standard deviations of the percentages of motiles and cocci are given in Tables 6 and 7 . Intragroup analysis showed that fluctuations in the percentages of motiles and cocci were significant after only one patient visit in the control group. The differences in the other group from the baseline up to 10 weeks were significant for both motiles and cocci. The decrease in the percentages of motiles and the increase in percentages of cocci showed higher levels of significance in both the doxycycline groups, in comparison with root planing. 
Table 1 Summary of statistical differences between all the groups at each visit for the measurement parameters determined by analysis of variance

\begin{tabular}{cllllll}
\hline \multicolumn{7}{c}{ Measurement Parameters } \\
\hline Week & PD & GS & BL & CF & Co & Mo \\
& & & & & NS & NS \\
0 & NS & NS & NS & NS & $*$ & $* *$ \\
1 & NS & NS & NS & NS & $* *$ & $* *$ \\
3 & NS & NS & $* *$ & NS & $* *$ & $* * *$ \\
6 & $*$ & $*$ & $* * *$ & $* *$ & $*$ & $* *$ \\
10 & $* *$ & $*$ & $* *$ & $* *$ & $*$ & \\
\hline
\end{tabular}

$\mathrm{PD}$, pocket depth; GS, gingival shrinkage; $\mathrm{BL}$, bleeding on probing; $\mathrm{CF}$, crevicular fluid flow; $\mathrm{Co}$, cocci; Mo, total motiles; NS, not significant

${ }^{*} \mathrm{p}<0.05,{ }^{* *} \mathrm{p}<0.01,{ }^{* * *} \mathrm{p}<0.001$

Table 2 Mean and standard deviation of the pocket depth for the treatment and control groups at the baseline (Visit 0) and at each visit up to $10 \mathrm{w}$ (Visit 4)

\begin{tabular}{|c|c|c|c|c|c|c|c|c|c|c|c|c|}
\hline \multirow{3}{*}{ Week } & \multicolumn{11}{|c|}{ Patient Groups } & \\
\hline & \multicolumn{3}{|c|}{ Control } & \multicolumn{3}{|c|}{ Root Planing } & \multicolumn{3}{|c|}{ Doxycycline(HPMC) } & \multicolumn{3}{|c|}{ Doxycycline (MC) } \\
\hline & $X$ & \pm & SD & $\mathrm{X}$ & \pm & SD & $\mathrm{X}$ & \pm & SD & $\mathrm{X}$ & \pm & SD \\
\hline 0 & 6.1 & \pm & 0.7 & 5.9 & \pm & 1.1 & 6.3 & \pm & 1.5 & 5.8 & \pm & 1.4 \\
\hline 1 & 6.0 & \pm & 0.8 & 5.5 & \pm & $1.3^{*}$ & 5.9 & \pm & $2.2 *$ & 5.5 & \pm & $1.1 *$ \\
\hline 3 & 5.8 & \pm & 1.0 & 5.1 & \pm & $1.5^{* *}$ & 5.6 & \pm & $1.8^{*}$ & 5.1 & \pm & $1.1^{* *}$ \\
\hline 6 & 5.9 & \pm & 1.1 & 4.6 & \pm & $1.4 * * *$ & 4.9 & \pm & $1.2 * * *$ & 4.8 & \pm & $0.9^{* *}$ \\
\hline 10 & 6.0 & \pm & 0.9 & 4.5 & \pm & $1.2 * * *$ & 5.0 & \pm & $1.0 * * *$ & 5.2 & \pm & $1.1^{*}$ \\
\hline
\end{tabular}

HPMC, Hydroxypropylmethylcellulose; MC, Methylcellulose

Statistical analysis; ${ }^{*} \mathrm{p}<0.05, * * \mathrm{p}<0.01,{ }^{*} * \mathrm{p}<0.001$

Table 3 Mean and standard deviation of gingival shrinkage for the treatment and control groups at the baseline (Visit 0) and at each visit up to $10 \mathrm{w}$ (Visit 4)

\begin{tabular}{|c|c|c|c|c|c|c|c|c|c|c|c|c|}
\hline \multirow{3}{*}{ Week } & \multicolumn{11}{|c|}{ Patient Groups } & \\
\hline & \multicolumn{3}{|c|}{ Control } & \multicolumn{3}{|c|}{ Root Planing } & \multicolumn{3}{|c|}{ Doxycycline (HPMC) } & \multicolumn{3}{|c|}{ Doxycycline (MC) } \\
\hline & $\mathrm{X}$ & \pm & SD & $\mathrm{X}$ & \pm & SD & $\mathrm{X}$ & \pm & SD & $\mathrm{X}$ & \pm & SD \\
\hline 0 & 7.7 & \pm & 2.4 & 7.3 & \pm & 2.6 & 7.3 & \pm & 2.9 & 7.5 & \pm & 2.8 \\
\hline 1 & 7.8 & \pm & 2.6 & 7.5 & \pm & 2.5 & 7.4 & \pm & 2.3 & 7.7 & \pm & 2.8 \\
\hline 3 & 7.9 & \pm & 2.6 & 7.9 & \pm & $2.5^{*}$ & 8.5 & \pm & $2.3^{* *}$ & 8.3 & \pm & $2.9 *$ \\
\hline 6 & 7.8 & \pm & 2.3 & 8.2 & \pm & $2.4^{* *}$ & 8.7 & \pm & $2.6^{* *}$ & 8.9 & \pm & $2.8^{* *}$ \\
\hline 10 & 7.8 & \pm & 3.1 & 8.5 & \pm & $2.7 * *$ & 8.5 & \pm & $2.2 * *$ & 8.5 & \pm & $2.8^{* *}$ \\
\hline
\end{tabular}

HPMC, Hydroxypropylmethylcellulose; MC, Methylcellulose

Statistical analysis ; ${ }^{*} \mathrm{p}<0.05, * * \mathrm{p}<0.01$ 
Table 4 Mean and standard deviation of bleeding score for the treatment and control groups at the baseline (Visit 0) and at each visit up to $10 \mathrm{w}$ (Visit 4)

\begin{tabular}{|c|c|c|c|c|c|c|c|c|c|c|c|c|}
\hline \multirow{3}{*}{ Week } & \multicolumn{11}{|c|}{ Patient Groups } & \\
\hline & \multicolumn{3}{|c|}{ Control } & \multicolumn{3}{|c|}{ Root Planing } & \multicolumn{3}{|c|}{ Doxycycline (HPMC) } & \multicolumn{3}{|c|}{ Doxycycline (MC) } \\
\hline & $\mathrm{X}$ & \pm & $\mathrm{SD}$ & $\mathrm{X}$ & \pm & SD & $\mathrm{X}$ & \pm & SD & $\mathrm{X}$ & \pm & SD \\
\hline 0 & 3.1 & \pm & 0.8 & 3.0 & \pm & 0.8 & 2.9 & \pm & 0.7 & 2.9 & \pm & 0.7 \\
\hline 1 & 3.0 & \pm & 0.8 & 2.5 & \pm & 0.7 & 2.8 & \pm & 0.8 & 2.6 & \pm & 0.5 \\
\hline 3 & 3.1 & \pm & 0.8 & 2.6 & \pm & $0.4^{*}$ & 2.2 & \pm & $0.4 * * *$ & 2.2 & \pm & $0.6 * *$ \\
\hline 6 & 2.9 & \pm & 0.7 & 1.7 & \pm & $0.5^{* *}$ & 1.7 & \pm & $0.6^{* * *}$ & 1.6 & \pm & $0.7 * * *$ \\
\hline 10 & 3.0 & \pm & 0.9 & 1.5 & \pm & $0.7^{* *}$ & 1.6 & \pm & $0.7 * * *$ & 1.7 & \pm & $0.8 * * *$ \\
\hline
\end{tabular}

HPMC, Hydroxypropylmethylcellulose; MC, Methylcellulose

Statistical analysis ; ${ }^{*} \mathrm{p}<0.05,{ }^{*} \mathrm{p}<0.01,{ }^{*} * \mathrm{p}<0.001$

Table 5 Mean and standard deviation of crevicular fluid flow in the treatment and control groups at the baseline (Visit 0) and at each visit up to $10 \mathrm{w}$ (Visit 4)

\begin{tabular}{|c|c|c|c|c|c|c|c|c|c|c|c|c|}
\hline \multirow{3}{*}{ Week } & \multicolumn{11}{|c|}{ Patient Groups } & \\
\hline & \multicolumn{3}{|c|}{ Control } & \multicolumn{3}{|c|}{ Root Planing } & \multicolumn{3}{|c|}{ Doxycycline (HPMC) } & \multicolumn{3}{|c|}{ Doxycycline (MC) } \\
\hline & $\mathrm{X}$ & \pm & SD & $\mathrm{X}$ & \pm & $\mathrm{SD}$ & $\mathrm{X}$ & \pm & SD & $\mathrm{X}$ & \pm & $\mathrm{SD}$ \\
\hline 0 & 2.0 & \pm & 0.7 & 1.8 & \pm & 0.8 & 1.6 & \pm & 0.6 & 1.7 & \pm & 0.7 \\
\hline 1 & 1.9 & \pm & 0.6 & 1.6 & \pm & $0.7^{*}$ & 1.2 & \pm & $0.5^{*}$ & 1.4 & \pm & $0.7 * *$ \\
\hline 3 & 1.7 & \pm & $0.6^{*}$ & 1.4 & \pm & $0.7 * *$ & 1.1 & \pm & $0.4 * *$ & 1.1 & \pm & $0.6 * * *$ \\
\hline 6 & 1.8 & \pm & 0.5 & 1.3 & \pm & $0.5^{* *}$ & 1.0 & \pm & $0.4 * *$ & 1.2 & \pm & $0.5^{* *}$ \\
\hline 10 & 2.0 & \pm & 0.6 & 1.1 & \pm & $0.4 * *$ & 0.9 & \pm & $0.3 * *$ & 1.1 & \pm & $0.4^{* *}$ \\
\hline
\end{tabular}

HPMC, Hydroxypropylmethylcellulose; MC, Methylcellulose

Statistical analysis; ${ }^{*} \mathrm{p}<0.05,{ }^{* *} \mathrm{p}<0.01,{ }^{* * *} \mathrm{p}<0.001$

Table 6 Mean and standard deviation of the percentage of curved and motile rods and spirochetes for the treatment and control groups at the baseline (Visit 0) and at each visit up to $10 \mathrm{w}$ (Visit 4)

\begin{tabular}{|c|c|c|c|c|c|c|c|c|c|c|c|c|}
\hline \multirow{3}{*}{ Week } & \multicolumn{11}{|c|}{ Patient Groups } & \\
\hline & \multicolumn{3}{|c|}{ Control } & \multicolumn{3}{|c|}{ Root Planing } & \multicolumn{3}{|c|}{ Doxycycline (HPMC) } & \multicolumn{3}{|c|}{ Doxycycline (MC) } \\
\hline & $X$ & \pm & SD & $X$ & \pm & $\mathrm{SD}$ & $X$ & \pm & SD & $\mathrm{X}$ & \pm & $\mathrm{SD}$ \\
\hline 0 & 29.9 & \pm & 10.4 & 28.9 & \pm & 12.4 & 28.2 & \pm & 12.1 & 26.4 & \pm & 13.3 \\
\hline 1 & 33.5 & \pm & 14.7 & 19.0 & \pm & 12.6 & 17.1 & \pm & $9.3^{*}$ & 15.3 & \pm & $9.8 * *$ \\
\hline 3 & 29.6 & \pm & 13.9 & 20.0 & \pm & $10.1^{*}$ & 13.3 & \pm & $8.9^{* *}$ & 13.4 & \pm & $8.3^{* *}$ \\
\hline 6 & 28.8 & \pm & 14.4 & 19.8 & \pm & $8.4^{*}$ & 11.9 & \pm & $10.2 * * *$ & 11.1 & \pm & $7.5^{* *}$ \\
\hline 10 & 31.8 & \pm & $10.7^{*}$ & 17.3 & \pm & $9.4 * *$ & 11.0 & \pm & $9.6^{* * *}$ & 11.6 & \pm & $6.3^{* *}$ \\
\hline
\end{tabular}

HPMC, Hydroxypropylmethylcellulose; MC, Methylcellulose

Statistical analysis; ${ }^{*} \mathrm{p}<0.05, * * \mathrm{p}<0.01, * * * \mathrm{p}<0.001$ 
Table 7 Mean and standard deviation of the percentage of cocci in the treatment and control groups at the baseline (Visit 0) and at each visit up to $10 \mathrm{w}$ (Visit 4)

\begin{tabular}{|c|c|c|c|c|c|c|c|c|c|c|}
\hline \multirow{3}{*}{ Week } & \multicolumn{9}{|c|}{ Patient Groups } & \\
\hline & \multicolumn{2}{|l|}{ Control } & \multicolumn{3}{|c|}{ Root Planing } & \multicolumn{2}{|c|}{ Doxycycline (HPMC) } & \multicolumn{3}{|c|}{ Doxycycline (MC) } \\
\hline & \pm & SD & $X$ & \pm & SD & \pm & SD & $X$ & \pm & SD \\
\hline 0 & $62.1 \pm$ & 12.5 & 58.9 & \pm & 14.8 & $57.3 \pm$ & 13.9 & 62.9 & \pm & 12.6 \\
\hline 1 & $58.7 \pm$ & 12.0 & 68.6 & \pm & $13.6^{*}$ & $69.5 \pm$ & $12.7 *$ & 73.4 & \pm & $13.7^{* *}$ \\
\hline 3 & $66.8 \pm$ & 13.9 & 71.8 & \pm & $17.6^{*}$ & $71.9 \pm$ & $12.1 * *$ & 75.1 & \pm & $8.0 * *$ \\
\hline 6 & $70.7 \pm$ & $13.1^{*}$ & 74.6 & \pm & $12.0^{*}$ & $73.5 \pm$ & $11.9^{* *}$ & 78.3 & \pm & $10.2^{* *}$ \\
\hline 10 & $62.9 \pm$ & 10.8 & 76.1 & \pm & $10.9 * *$ & $74.0 \pm$ & $11.7 * *$ & 73.0 & \pm & $8.9^{*}$ \\
\hline
\end{tabular}

HPMC, Hydroxypropylmethylcellulose; MC, Methylcellulose

Statistical analysis ; ${ }^{*} \mathrm{p}<0.05,{ }^{*} \mathrm{p}<0.01$

\section{Discussion}

Various attempts have been made to control subgingival plaque in the treatment of periodontal disease ${ }^{[10,27,28]}$. There have been a number of clinical and bacteriological studies on the addition of systemic antibiotics to subgingival mechanical debridement ${ }^{[11-13]}$.

In periodontal antibiotic therapy, local administration is superior to systemic administration because the latter involves some restrictions as to the dose level and duration of dosing ${ }^{[1,29]}$.

In recent years, many basic clinical studies on local drug delivery systems have been performed using various materials as carrier substances ${ }^{[15-20,30-32]}$. Some investigators have used resorbable ${ }^{[20]}$ and nonresorbable ${ }^{[15-17]}$ base materials to allow antibiotics and antibacterial drugs to stay in the periodontal pocket for a long period. Although many of the polymers employed have favorable properties such as excellent biocompatibility and ease of handling, resorbable polymers may be preferable as base materials because of their ability to dissolve and be absorbed in the periodontal pocket after a certain period, thus avoiding damage to regenerating tissues at the treated $\operatorname{sit}^{[14,20,33]}$. In our study, we used resorbable HPMC and MC as carrier substances to provide prolonged release of doxycycline. According to Noguchi' ${ }^{[7]}$ results changes in clinical parameters, such as the reduction of probing depth and bleeding on probing were observed only in pockets in which tetracycline was administered. However, the prevalence of spirochetes and motile rods was markedly reduced, both in tetracycline- and chlorhexidine- administered pockets.

In our study, changes in clinical parameters such as reduction of pocket depth, bleeding, crevicular fluid flow and gingival shrinkage in the doxycycline groups were more marked than in the root planing group after $10 \mathrm{w}$. However, the prevalence of spirochetes and motile rods was markedly reduced in both the doxycycline groups.

In this in vitro model, the maximum percentage of doxycycline was released from both HPMC and MC in the first $12 \mathrm{~h}$. Doxycycline release from HPMC membranes seems to be greater than from MC membranes. According to the results at $24 \mathrm{~h}$, the rate of drug release was around $30 \mu \mathrm{g} / \mathrm{h}$ for HPMC and $5 \mu \mathrm{g} / \mathrm{h}$ for MC, in contrast to Noguchi's study where no release of drug was detectable in $24 \mathrm{~h}$ after insertion of $1 \%$ tetracycline- or $5 \%$ chlorhexidine- loaded HPC (hydroxypropylcellulose) strips.

Larsen $^{[33]}$ evaluated the release of doxycycline from bioabsorbable materials (Surgicel, Tissell, Colla Cote) and acrylic strips in an in vitro study. Surgicel produced very high concentrations, above $250 \mu \mathrm{g} / \mathrm{ml}$, throughout the study. The doxycycline release from Tissell was reduced from above $250 \mu \mathrm{g} / \mathrm{ml}$ on day 1 to about $25 \mu \mathrm{g} / \mathrm{ml}$ on days 4 and 5 . The doxycycline release from Colla Cote and the acrylic strip decreased more rapidly from above $250 \mu \mathrm{g} / \mathrm{ml}$ on the first day to below $5 \mu \mathrm{g} / \mathrm{ml}$ on days 3 and 4 , respectively. These 
higher rates of release appear to support our results.

In conclusion, our study has shown that two different resorbable base materials containing doxycycline can have a marked effect on clinical and microbiological parameters after $10 \mathrm{w}$.

Further studies will be necessary to establish the contribution of this method to conventional periodontal therapy.

\section{References}

[ 1 ] Slots, J.: Subgingival microflora and periodontal disease, J. Clin. Periodontol., 6, 351-382, 1979

[ 2 ] Slots, J., Emrich, L.J., Genco, R.J. and Rosling, B. G.: Relationship between some subgingival bacteria and periodontal pocket depth and gain or loss of periodontal attachment after treatment of adult periodontitis, J. Clin. Periodontol., 12, 540-552, 1985

[ 3 ] Dzink, J. L., Tanner, A. C. R., Haffajee, A. D. and Socransky, S. S.: Gram-negative species associated with active destructive periodontal lesions, J. Clin. Periodontol., 12, 648-659, 1985

[ 4 ] Slots, J.: Bacterial specificity in adult periodontitis. A summary of recent work, J. Clin. Periodontol., 13, 912-917, 1986

[ 5 ] Haffajee, A. D., Socransky, S. S., Dzink, J. L., Taubman, M. A., Ebersole, J. L. and Smith, D. J.: Clinical, microbiological and immunological features of subjects with destructive periodontal diseases, J. Clin. Periodontol., 15, 240-246, 1988

[ 6 ] Dzink, J. L., Socransky, S. S. and Haffajee, A. D.: The predominant cultivable microbiota of active and inactive lesions of destructive periodontal diseases, J. Clin. Periodontol., 15, 316-323, 1988

[ 7 ] Waerhaug, J.: The interdental brush and its place in operative crown and bridge dentistry, J. Oral. Rehabil., 3, 107-113, 1976

[ 8 ] Waerhaug, J.: Healing of the dento-epithelial junction following subgingival plaque control. II. As observed on extracted teeth, J. Periodontol., 49, 119-134, 1978

[ 9 ] Reinhardt, R. A., Johnson, G. K. and Tussing, G. J.: Root planing with interdental papilla reflection and fiber optic illumination, J. Periodontol., 56, 721-726, 1985

[10] Hull, P. S.: Chemical inhibition of plaque, J. Clin. Periodontol., 7, 431-442, 1980

[11] Ciancio, S. G.: Chemotherapeutics in periodontics, Dent. Clin. N. Am., 24, 813-826, 1980

[12] Genco, R. J.: Antibiotics in the treatment of periodontal disease, J. Periodontol., 52, 545-558, 1981

[13] Addy, M.: Rationale for chemotherapy in the treatment of periodontal disease. In Periodontology Today, Guggenheim, ed., , Karger, Basel 281-289, 1988

[14] Mirth, D. B.: Controlled-release therapeutic systems: Technology applicable to the treatment of oral disease, Adv. Dent. Res., 1, 119-130, 1987

[15] Addy, M., Rawle, L., Newman, M. N. and Coventry, J. F.: The development and in vitro evaluation of acrylic strips and dialysis tubing for local drug delivery, J. Periodontol., 53, 693-699, 1982

[16] Goodson, J. M., Holbrow, D., Dunn, R. L., Mogan, P. and Dunham, S.: Monolithic tetracycline-containing fibers for controlled delivery to periodontal pockets, J. Periodontol., 54, 575-579, 1983

[17] Lindhe, L., Heijl, L., Goodson, J.M. and Socransky, S. S.: Local tetracycline delivery using hollow fiber devices in periodontal therapy, J. Clin. Periodontol., 6, 141-149, 1979

[18] Minabe, M., Uematsu, A., Nishijima, K., Tomomatsu, E., Tamura, T., Hori, T., Umemoto, T. and Hino, T.: Application of a local drug delivery system to periodontal therapy. I. Development of collagen preparations with immobilized tetracycline, J. Periodontol., 60, 113-118, 1989

[19] Minabe, M., Takekuchi, K., Tamura, T., Mori, T. and Umemoto, T.: Subgingival administration of tetracycline on a collagen film, J. Periodontol., 60, 552-556, 1989

[20] Noguchi, T., Fukuda, M. and Ishikawa, I.: Periodontal treatment by local drug delivery using resorbable base material, Adv. Dent. Res., 2, 401-404, 1988

[21] Golub, L. M., Wolff, M. and Lee, M. M.: Further evidence that tetracyclines inhibit collagenase activity in human crevicular fluid and from other mammalian sources, J. Periodont. Res., 20, 12-23, 1985 
[22] Peros, W. J., Etherden, I., Gibbons, R. J. and Skobe, Z.: Alteration of fimbriation and cell hydrophobicity by sublethal concentrations of tetracycline, J. Periodont. Res., 20, 24-30, 1985

[23] Robbins, M., Marais, R., Felmingham, D. and Ridgway, G. L.: The in vitro activity of doxycycline and minocycline against anaerobic bacteria, J. Antimicrob. Chemother., 20, 379-382, 1987

[24] Loe, M. and Holm-Pederson, P.: Absence and presence of fluid from normal and inflamed gingivae, Periodontics, 3, 171-177, 1965

[25] Listgarten, M. A. and Hellden, L.: Relative distribution of bacteria at clinically healthy and periodontally diseased sites in humans, J. Clin. Periodontol., 5, 115-132, 1978

[26] Muhlemann, H. R. and Son. S.: Gingival sulcus bleeding- a leading symptom in initial gingivitis, Helv. Odontol. Acta, 15, 107-113, 1971

[27] Rosling, B. G., Slots, J., Webber, R. C., Christersson, L. A. and Genco, R. J.: Microbiological and clinical effects of topical subgingival anti-microbial treatment on human periodontal disease, J. Clin. Periodontol., 10, 487-514, 1983

[28] Newman, H. N.: Modes of application of anti-plaque chemicals, J. Clin. Periodontol., 13, 965-974, 1986

[29] Goodson, J. M.: Dental applications. In Medical Applications of Controlled Release Technology, Langer, R. S. and Wise, D.L., eds., vol II, Ch. 6., CRC Press, Boca Raton, FL.

[30] Higashi, K., Morisaki, K. and Hayashi, S.: Local ofloxacin delivery using a controlled-release insert (PT-01) in the human periodontal pocket, J. Periodont. Res., 25, 1-5, 1990

[31] Kimura, S., Toda, M., Shimabukuro, Y., Kitamura, M., Fujimoto, N., Miki, Y. and Okada, M.: Topical chemotherapy in human periodontitis using a new controlled-release insert containing ofloxacin. I. Microbiological observation, J. Periodont. Res., 26, 33-41, 1991

[32] Yamagami, H., Takamori, A., Sakamoto, T. and Okada, M.: Intrapocket chemotherapy in adult periodontitis using a new controlled release insert containing ofloxacin (PT-01), J. Periodontol., 63, 26, 1992

[33] Larsen, T.: In vitro release of doxycycline from bioabsorbable materials and acrylic strips, $J$. Periodontol., 61, 30-34, 1990 